\title{
DESENVOLVIMENTO DE MÉTODO ESPECTROFOTOMÉTRICO PARA DETERMINAÇÃO DE N-[(FOSFONOMETIL) GLICINA] (GLIFOSATO) EM LATOSSOLO DE PATY DO ALFERES/RJ
}

\author{
G. B. SCHMIDT ${ }^{1}$, L. J. SANTOS ${ }^{2}$, J. M. C. LEITE $^{2}$, B. A. JORDÃO ${ }^{2}$, D. M. TORRES ${ }^{3}$ e \\ C.E. CARDOSO ${ }^{1,2,4}$ \\ ${ }^{1}$ Universidade Severino Sombra (USS), Curso de Química Industrial. \\ ${ }^{2}$ Universidade Severino Sombra (USS), Curso de Engenharia Química. \\ ${ }^{3}$ Pontifícia Universidade Católica do RJ (PUC-Rio), Curso de Mestrado em Engenharia de Materiais \\ e de Processos Químicos e Metalúrgicos. \\ ${ }^{4}$ Universidade Severino Sombra (USS), Curso de Mestrado Profissional em Ciências Ambientais \\ E-mail para contato: cardoso221@yahoo.com.br
}

\begin{abstract}
RESUMO - O município de Paty do Alferes/RJ é caracterizado por propriedades rurais que possuem relevo acidentado de Latossolos, Podzólicos e Cambissolos. São bem drenados, argilosos e de baixa fertilidade. Para compensar a baixa produtividade, os produtores utilizam agrotóxicos para o controle das pragas. Dentre eles, está a [n-(fosfonometil)glicina] ou glifosato, cujo uso indiscriminado pode comprometer a qualidade do solo e das águas. Neste trabalho, alternativamente às técnicas cromatográficas, foi desenvolvido um método espectrofotométrico baseado na reação do glifosato com o dissulfeto de carbono $\left(\mathrm{CS}_{2}\right)$ e posterior complexação com cálcio $\left(\mathrm{Ca}^{2+}\right)$. $\mathrm{O}$ estudo foi conduzido após um planejamento fatorial que otimizou as concentrações dos reagentes usados na complexação. Utilizandose essa metodologia e um lisímetro de bancada, foi possível quantificar o glifosato no lixiviado de um latossolo dessa região, indicando que este método é simples, rápido e pode ser utilizado com sucesso.
\end{abstract}

\section{INTRODUÇÃO}

O município de Paty do Alferes (RJ) é caracterizado por pequenas propriedades rurais que possuem relevo acidentado de Latossolos, Podzólicos e Cambissolos bem drenados, argilosos, de baixa fertilidade e suscetíveis à erosão (Ramalho et al., 2000). A produtividade agrícola na região tem decrescido anualmente devido ao desmatamento, práticas impróprias e uso abusivo de agrotóxicos.

O comércio mundial de agrotóxicos cresce a cada ano. Embora muitas mudanças e inovações surjam conforme as necessidades do mercado (culturas transgênicas, por exemplo), o uso de herbicidas é destacado visto que a maioria destas inovações não impede o florescimento de ervas daninhas no campo. Desde que foi introduzido no mercado, o uso do herbicida glifosato $\left(\mathrm{C}_{3} \mathrm{H}_{8} \mathrm{NO}_{5} \mathrm{P}\right)$ tornou-se prática frequente, representando mais de $60 \%$ do mercado mundial de herbicidas não seletivos (Coutinho e Mazo, 2005). O glifosato é um herbicida não-seletivo e de ação sistêmica que atua como inibidor da atividade da 5-enolpiruvilshiquimato-3-fosfato síntese, que é catalisadora de uma das 


\section{9 a 22 de outubro de 2014 \\ Florianópolis/SC}

reações de síntese dos aminoácidos aromáticos fenilalanina, tirosina e triptofano. Influencia, também, outros processos, tais como a inibição da síntese de clorofila, estimula a produção de etileno, reduz a síntese de proteínas e eleva a concentração do ácido indol-3-acético (IAA). De acordo com Galli e Montezuma (2005), o glifosato é degradado no solo, sendo característica importante sua capacidade de ser adsorvido pelas partículas de solo e ali permanecer até a completa degradação. Sua meia-vida média (tempo médio necessário para que metade da quantidade aplicada do produto seja degradada) é de cerca de 32 dias (Galli e Montezuma, 2005). Assim, sabendo-se que a utilização não criteriosa desse produto pode comprometer a qualidade do solo, das águas, dos alimentos e, consequentemente, dos seres humanos, esse trabalho teve como objetivo desenvolver uma metodologia analítica espectrofotométrica para avaliar a presença do agrotóxico glifosato em soluções aquosas e no lixiviado de um latossolo oriundo dessa região.

\section{MATERIAIS E MÉTODOS}

\subsection{Amostragem}

Para a coleta das amostras de solo foi utilizado o procedimento preconizado pela Embrapa Solos (EMBRAPA, 2013). Foram feitas coletas mensais durante o ano de 2013 e para armazenagem, utilizados sacos plásticos resistentes, identificados por escrita direta. A propriedade foi dividida em áreas uniformes quanto à cor, topografia e textura para a retirada das amostras, não tendo recebido adubações nem calagem. A área foi percorrida em ziguezague, retirando-se com um trado, amostras de 15 a 20 pontos diferentes, que foram colocadas juntas em baldes plásticos limpos e secos. Todas as amostras individuais foram bem misturadas, tendo sido retirada uma amostra final de cerca de $10 \mathrm{~kg}$. As amostras foram secas ao ar por 48 horas e passadas em peneira com abertura da malha de 2,0 $\mathrm{mm}$.

\subsection{Soluções e reagentes}

Todos os reagentes utilizados apresentavam, no mínimo, grau analítico. Ácido nítrico concentrado $\left(\mathrm{HNO}_{3}\right)$ da Cromaline (Brasil), ácido clorídrico concentrado $(\mathrm{HCl})$ da Vetec (Brasil), hidróxido de sódio $(\mathrm{NaOH})$ a $30 \%(\mathrm{~m} / \mathrm{V})$ da Vetec (Brasil), glifosato comercial a $48 \%(\mathrm{~m} / \mathrm{V})$ e padrão de glifosato da Sigma-Aldrich (EUA), dissulfeto de carbono $\left(\mathrm{CS}_{2}\right)$ da Fluka Chemika (França) e cloreto de cálcio $\left(\mathrm{CaCl}_{2}\right)$ PA da Reagen (Brasil), etanol PA (Merck), cloreto de potássio ( $\mathrm{KCl}$ ) da Isofar (Brasil), foram utilizados no preparo das soluções e dos complexos. Para o preparo das soluções de $\mathrm{CS}_{2}$ $1 \%(100 \mathrm{~mL})$ utilizou-se clorofórmio para avolumar e para as de cloreto de cálcio $\left(10000 \mu \mathrm{g} \cdot \mathrm{mL}^{-1} \mathrm{Ca}^{2+}\right.$, $50 \mathrm{~mL})$ e nitrato de cobre $\left(10000 \mu \mathrm{g} \cdot \mathrm{mL}^{-1} \mathrm{Cu}^{2+}, 50 \mathrm{~mL}\right)$, água destilada.

\subsection{Procedimento de complexação do glifosato}

O material utilizado em todos os procedimentos foi previamente lavado com detergente neutro, enxaguado com água destilada e seco em estufa (Estufa de Secagem e Esterilização Mod. 315SE FANEM, Brasil). A metodologia analítica desenvolvida consistiu na adição de 1,0 mL da solução de glifosato a $5 \mathrm{~mL}$ de solução de $\mathrm{CS}_{2} 2,7 \%$ (V/V) preparada em clorofórmio seguido de trinta segundos de agitação em vortex. Após a agitação, foi adicionado $1 \mathrm{~mL}$ de uma solução de $\mathrm{Ca}^{2+} 215 \mu \mathrm{g} \mathrm{mL} \mathrm{m}^{-1}$ preparada em meio amoniacal $(\mathrm{pH} 12,0)$. $\mathrm{O}$ valor de $\mathrm{pH}$ foi obtido ao término do preparo da solução de 
$\mathrm{Ca}^{2+}$ através de potenciômetro digital (MARTE MB-10, Brasil), previamente calibrado. A solução foi agitada por mais trinta segundos, mantida em repouso no escuro por quinze minutos e teve a fase orgânica separada e avolumada com etanol para $10 \mathrm{~mL}$. Finalmente, o complexo amarelo formado foi separado e levado a um espectrofotômetro UV/Vis para medição da absorbância em $339 \mathrm{~nm}$. Em todos os casos foram utilizados tubos com tampa para evitar perdas por evaporação dos solventes.

\subsection{Preparo das curvas analíticas e das amostras fortificadas}

Para construção das curvas analíticas foram adicionadas alíquotas da solução estoque de N[(fosfonometil) glicina] padrão $48 \%(\mathrm{~m} / \mathrm{V})$ em balões volumétricos de $25 \mathrm{~mL}$ até a obtenção de concentrações iguais a 0,$1 ; 0,2 ; 0,4 ; 0,6 ; 0,8$ e 1,0\% (m/V). Após serem avolumados com água destilada, conduziu-se a reação de complexação descrita no item 2.3. As curvas foram traçadas (pontos em triplicata real) e os testes de validação e de recuperação feitos conforme o caso. Todos os dados foram manipulados nos aplicativos Excel@ da Microsoft e no Statistica 7.0 da Statsoft.

\subsection{Construção dos lisímetros}

Para aplicação da metodologia desenvolvida e quantificação do glifosato no lixiviado, foram construídos dois lisímetros de bancada (um para utilização como "controle" ou branco e outro para as adições de glifosato). Foram utilizados dois tubos de PVC $(150 \mathrm{~cm} \times 15 \mathrm{~cm})$, quatro CAP de $16 \mathrm{~cm}$ de diâmetro da Krona, cola para PVC da Pulvitec (Brasil), duas torneiras de plástico com vedação da Herc. $\mathrm{Na}$ região inferior do tubo e imediatamente acima da torneira foi fixado (internamente) um funil (adaptado de uma garrafa PET) preenchido com pedra brita e cascalho para coleta do lixiviado. Os lisímetros foram colocados em um suporte de madeira construído para esse fim (Figura 1).
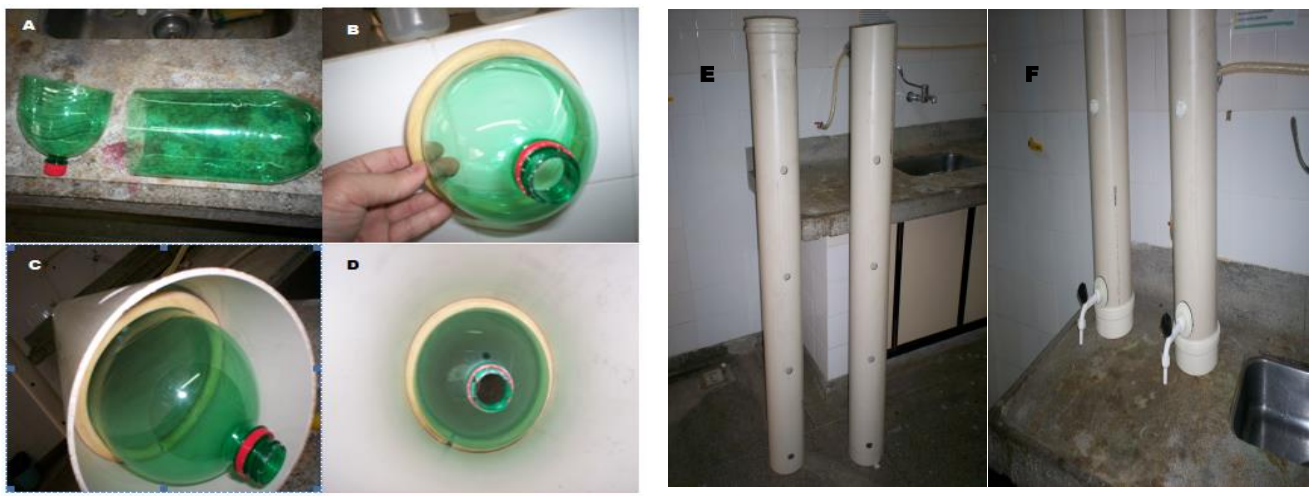

Figura 1 - Etapas da construção dos lisímetros. A e B: funil feito com garrafa PET; C e D funil fixado no tubo de PVC; E: tubos de PVC; F: lisímetros prontos.

\subsection{Simulação de chuva para coleta do lixiviado}

Para a simulação de chuva levou-se em conta o ano hidrológico de Paty do Alferes e, considerando-se que no mês que mais chove o índice pluviométrico supera os $60 \mathrm{~mm}$ (IBGE, 2013), todos os experimentos foram conduzidos com este valor. Após a coleta do lixiviado na parte inferior do 


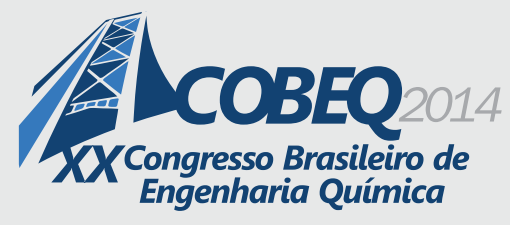

19 a 22 de outubro de 2014
Florianópolis/SC

lisímetro (frasco plástico), as mesmas foram mantidas em refrigerador por, no máximo, 24 h. Imediatamente antes do uso e após atingirem a temperatura ambiente, as amostras foram filtradas em papel de filtro comum (papel Qualy $40 \mathrm{~cm}$ ) e o complexo formado nas condições otimizadas previamente, sempre em triplicata.

\section{RESULTADOS E DISCUSSÃO}

A molécula do glifosato apresenta elevada polaridade e ausência de cromóforo. Por estes motivos, a determinação do glifosato por cromatografia ou espectrofotometria necessita de adaptações que permitam sua detecção. Tais adaptações incluem, basicamente, reações de derivatização ou, ainda, alteração de alguma propriedade física que possa ser relacionada à quantidade de glifosato na amostra. Dong e colaboradores (1997) e Zhemchuzhin e Gorobets (1989), determinaram glifosato em águas utilizando métodos espectrofotométricos. No primeiro caso, as amostras foram diluídas com água destilada, seguida de reações com EDTA dissódico, nitrito de sódio e ácido sulfúrico, iodeto de potássio e amido a $15^{\circ} \mathrm{C}$ e a absorbância medida em $550 \mathrm{~nm}$. No segundo caso foi utilizada a reação com água de bromo para formação de brometo do herbicida e, em seguida, tampão pirofosfato, solução de álcooldehidrogenase e $\mathrm{NAD}^{+}$, em etanol a $50 \%$.

Em um outro trabalho, Jan e colaboradores (2009) usaram a reação do glifosato com o dissulfeto de carbono a $1 \%$ e o complexaram com o íon cobre. O complexo formado teve a absorbância medida em um espectrofotômetro a $435 \mathrm{~nm}$. Este foi o ponto de partida utilizado nesse trabalho e diversos testes foram conduzidos no sentido de otimizar os volumes e as concentrações dos reagentes para a formação do complexo Glifosato - Metal, utilizando-se o cálcio como complexante. Assim, preliminarmente, fezse reagir $1,0 \mathrm{~mL}$ de glifosato a $1 \%(\mathrm{~m} / \mathrm{V})$ com volumes variáveis de $\mathrm{CS}_{2}$ a $1 \%$ (1 a $5 \mathrm{~mL}$ ), objetivandose converter o grupo amino do agrotóxico em ácido ditiocarbâmico. $\mathrm{O}$ ácido formado foi complexado com volumes variáveis $(100 \mu \mathrm{L}$ a $1000 \mu \mathrm{L})$ de uma solução de $\mathrm{Ca}^{2+} 1000 \mu \mathrm{g} \mathrm{mL}^{-1}$ em pH 12,0. A N[(fosfonometil) glicina] (glifosato) é um agrotóxico peculiar que depende principalmente do $\mathrm{pH}$, pois este é capaz de mudar sua conformação molecular, dificultando sua análise em amostras de solo e água. Em pH abaixo de 0,8, a maior parte do glifosato se apresenta com uma protonação no sítio da amina. Em pH 0,8, cerca de 50\% das moléculas apresentam uma protonação e as demais moléculas com uma dissociação no grupo fosfato. A partir deste valor até $\mathrm{pH} 2,2$, tem-se predominância da forma molecular, com uma dissociação (-PO $\left.{ }_{2} \mathrm{H}-\right)$ e uma protonação $\left(-\mathrm{NH}^{2+}\right.$-), sendo que, em pH 2,2, 50\% do composto já possui duas dissociações, embora mantenha a protonação no grupamento amina. Entre pH 2,2 e 5,4, o herbicida se mostra com predominância da forma com duas dissociações, tendo, do mesmo modo, $50 \%$ das moléculas com três dissociações em $\mathrm{pH}$ 5,5. A partir de $\mathrm{pH} 5,5$ até 10,2, têm-se três dissociações. Neste $\mathrm{pH}$ ocorrem as formas com três e quatro dissociações. Acima de $\mathrm{pH} 11 \mathrm{o}$ glifosato se apresenta totalmente dissociado. Tal comportamento justifica, portanto, porque os experimentos de complexação com $\mathrm{Ca}^{2+}$ foram conduzidos em $\mathrm{pH}$ 12. Estes estudos preliminares mostraram bons

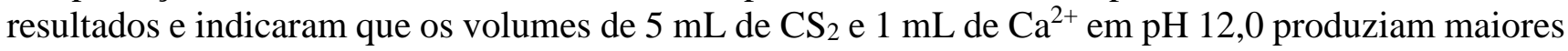
leituras de absorbância.

Em seguida, para otimizar as concentrações dos reagentes $\left(\mathrm{CS}_{2}\right.$ e $\left.\mathrm{Ca}^{2+}\right)$, foi utilizado um planejamento fatorial do tipo Composto Central. No método utilizado (análise da superfície de resposta) foi realizado um planejamento fatorial que empregou 13 experimentos. A modelagem foi feita 
ajustando-se os modelos mais simples, como o linear e o quadrático. Adicionalmente, as curvas de nível serviram para definir melhor a região de máximo da variável de resposta (absorbância). Pode-se identificar, também, os pontos do planejamento em que a resposta parece ser mais sensível às mudanças. As respostas para os 13 ensaios, expressas em valores médios de três repetições, foram obtidas após um planejamento fatorial $3^{2}$ mostrado na Tabela 1.

Tabela 1 - Planejamento fatorial $3^{2}$

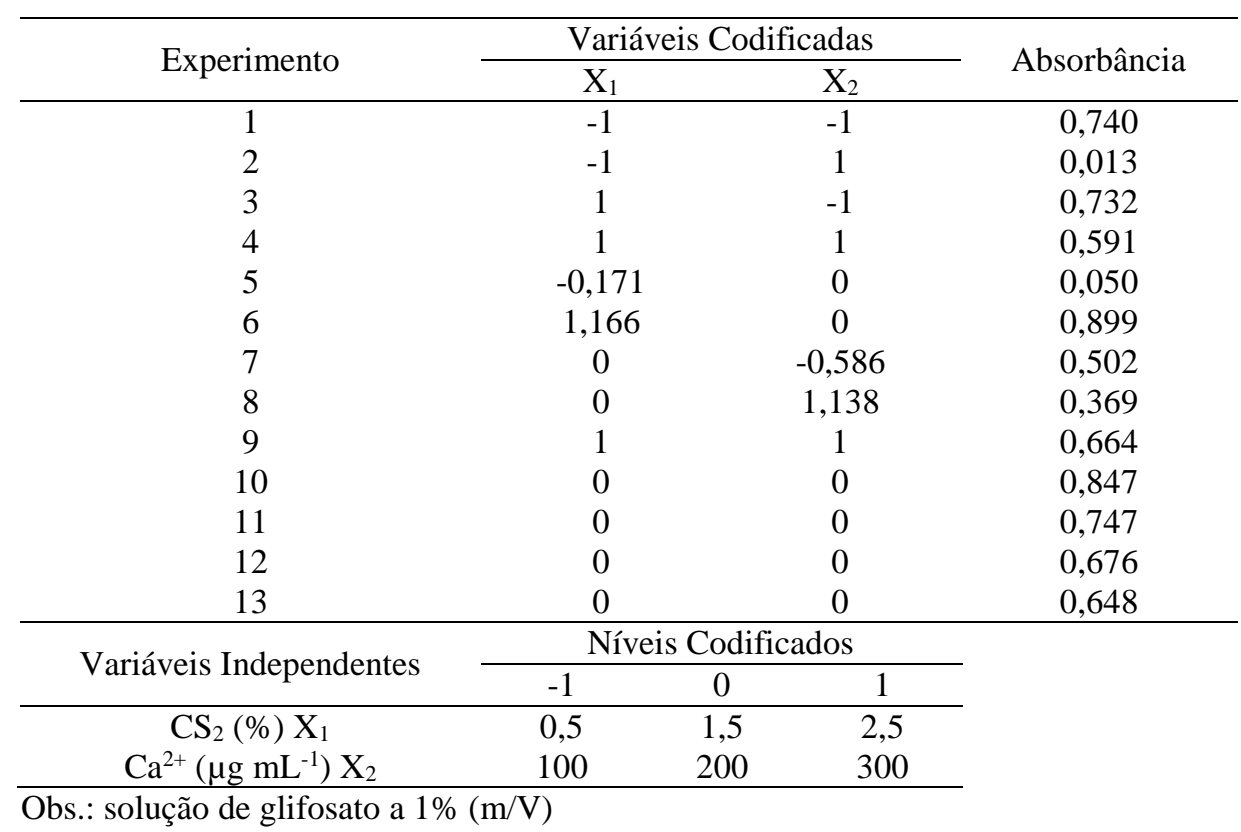

A análise da variância indicou haver relevância estatística $(\alpha=5 \%)$ de ambos os fatores $\left(\mathrm{CS}_{2} \mathrm{e}\right.$ $\left.\mathrm{Ca}^{2+}\right)$, isto é, ambos afetam de maneira significativa a absorbância do complexo formado $\left(\mathrm{F}_{\text {calculado }}>\mathrm{F}_{\text {crítico }}\right)$ quando o modelo linear foi adotado. $\mathrm{O}$ modelo quadrático e a interação entre os dois fatores não se mostraram relevantes e foram desprezados na região estudada. A Figura 2 mostra as curvas de nível obtidas a partir da superfície de resposta. Essas curvas foram bastante elucidativas e forneceram informações a respeito das condições de operação do processo. Se maiores valores de absorbância forem desejados (região vermelha no gráfico), deve-se usar os níveis mais altos da variável $\left[\mathrm{CS}_{2}\right]$ e níveis intermediários da $\left[\mathrm{Ca}^{2+}\right]$ (resultando em maiores leituras de absorbância e melhores parâmetros analíticos de mérito). Pela análise desses gráficos, percebe-se, portanto, que os melhores resultados podem ser obtidos quando $1,0 \mathrm{~mL}$ da solução de glifosato for adicionado a $5 \mathrm{~mL}$ de $\mathrm{CS}_{2} 2,7 \%$ (eixo x) e $1 \mathrm{~mL} \mathrm{Ca}^{2+} 215 \mu \mathrm{g} \mathrm{mL}^{-1}$ (eixo y) em $\mathrm{pH} 12,0$. Nessas condições, foram traçadas as curvas analíticas e realizados os experimentos de validação da metodologia.

A maioria dos órgãos reguladores do Brasil e de outros países exige a validação da metodologia analítica e, para isso, tem estabelecido documentos oficiais que são diretrizes a serem adotadas no processo de validação (INMETRO, 2003). Assim, a faixa de trabalho escolhida para a curva analítica foi de 0,1 a $1,0 \%(\mathrm{~m} / \mathrm{V})$ e foram traçadas três curvas analíticas em três dias diferentes. 


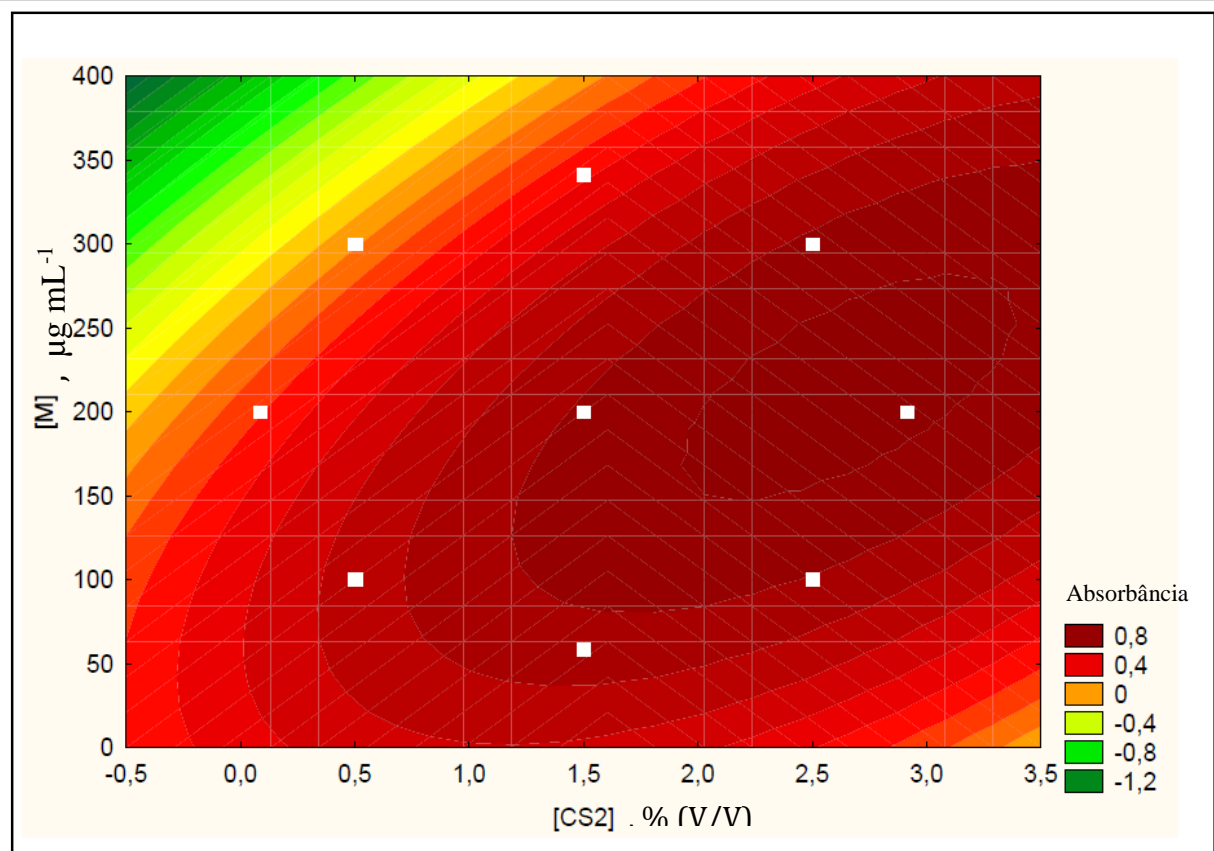

Figura 2 - Curvas de Nível obtidas no planejamento fatorial.

As premissas relativas à linearidade foram atendidas quando se trabalhou com essas curvas e , para cada curva após a remoção dos outliers (teste de Grubbs), foi confirmado que os resíduos da regressão seguiam a distribuição normal, não apresentavam autocorrelação, eram independentes e homoscedásticos. As regressões foram significativas $(\mathrm{p}<0,001)$ e não houve desvio da linearidade ( $\mathrm{p}>0,05)$ em nenhuma delas. Os resultados obtidos demonstraram que não houve diferença significativa ( $5 \%$ de probabilidade) entre as inclinações. Apesar disso, pode-se inferir que o erro humano, as condições climáticas do dia, a volatilidade do $\mathrm{CS}_{2}$, entre outros fatores, influenciam no preparo das curvas e os resultados das inclinações devem ser checados com frequência. Foi aplicado, também, o teste de resíduos padronizados (teste de Jacknife) para as curvas em solvente e na matriz (lixiviado do solo contido no lisímetro). Não foram encontrados outliers (teste de Grubbs) para a curva preparada em solvente e, para a curva preparada na matriz foram encontrados 2 outliers que foram removidos do estudo. As inclinações e interseções das curvas de solventes foram comparadas com aquelas estimadas para as curvas de matriz e não foram constatadas diferenças significativas (5\% de probabilidade) entre as inclinações e as interseções das curvas. Para verificar a seletividade do método, foram analisadas amostras do lixiviado do lisímetro "controle". As absorbâncias foram variáveis (em média 0,0501), mas sempre menores que as absorbâncias obtidas no estudo da linearidade para o menor nível da curva (média 0,1224). As amostras provenientes desse estudo (brancos) também não apresentaram cor amarela, que é indicativo da presença do complexo Glifosato-Metal, ao contrário das amostras contaminadas com o nível mais baixo $(0,1 \%, \mathrm{~m} / \mathrm{V})$. Mesmo em concentrações baixas, em torno de $0,1 \%(\mathrm{~m} / \mathrm{V})$, a cor amarela resultante do complexo formado é bastante visível e evidente. Assim, para o estudo da seletividade a resposta indistinguível dos padrões e das amostras adicionadas de padrões foi considerada suficiente. 
Os resultados de recuperação foram avaliados quanto à presença de outliers pelo teste de Grubbs e, após esse diagnóstico, os resíduos obtidos pela diferença entre a recuperação média e os valores individuais de recuperação obtidos para cada nível de concentração, apresentaram distribuição normal (teste de Ryan e Joiner, p>0,10) e homoscedasticidade (teste F de Levene, p>0,05). A inexatidão e a precisão seguiram os parâmetros estabelecidos pela Sanco/10684/2009, com aceitabilidade para validação de método na faixa de 70 a $120 \%$, com desvio padrão relativo menor e igual a $20 \%$, respectivamente. O limite de detecção (LD) do método foi de $0,008 \%(\mathrm{~m} / \mathrm{V})$. Este foi o nível em que o complexo foi detectado visualmente pela evidência da cor amarela e apresentou absorbância superior a 3 vezes às médias do branco do experimento. Vale ressaltar que obter o LD pela recuperação mostrou-se mais seguro, já que foi neste nível que houve evidências da presença do complexo amarelo, indicando precisão apesar de não ser possível quantificar o glifosato com segurança (falta de exatidão). Para o limite de quantificação ( L Q ) foi considerada a menor concentração do analito determinada com precisão e exatidão sob as condições otimizadas. Neste caso o limite de quantificação do método foi de $0,05 \%(\mathrm{~m} / \mathrm{V})$, que é o nível mais baixo em que ocorreu precisão e exatidão aceitáveis.

Para testar a metodologia desenvolvida, o lixiviado do latossolo foi coletado no lisímetro após a simulação de chuva. Estes estudos demonstraram que, no primeiro dia de aplicação do glifosato, a massa drenada após a percolação (1,30 $\mathrm{m}$ de profundidade e índice pluviométrico de $60 \mathrm{~mm})$ foi cerca de $3 \%$ do total aplicado (Tabela 2).

Tabela 2 - Testes de quantificação e recuperação do glifosato lixiviado no lisímetro

\begin{tabular}{cccc} 
& $\%(\mathrm{~m} / \mathrm{V})$ adicionada* & $\%(\mathrm{~m} / \mathrm{V})$ encontrada & Recuperação $(\%)$ \\
\hline 1 & 4,3 & $0,1 \pm 0,05$ & 2,3 \\
\hline 2 & 5,5 & $0,2 \pm 0,03$ & 3,6 \\
\hline 3 & 6,1 & $0,15 \pm 0,05$ & 2,4 \\
\hline \multicolumn{4}{c}{$*$ média de três determinações. }
\end{tabular}

\section{CONCLUSÕES}

O glifosato apresenta propriedades características, bastante diferentes da maioria dos outros agrotóxicos e, por ser um herbicida de amplo espectro, tornou-se o mais utilizado no mundo, aumentando a necessidade de metodologias alternativas de monitoramento. Neste trabalho, resultados obtidos neste trabalho permitiram concluir que a utilização da metodologia espectrofotométrica baseada na complexação do glifosato com o $\mathrm{Ca}^{+2}$ é bastante eficaz na avaliação qualitativa e quantitativa desse agrotóxico. A análise das curvas de nível geradas a partir do modelo ajustado (Planejamento Fatorial tipo Composto Central) permitiu verificar as combinações dos parâmetros dos níveis máximo e mínimo que influenciam o resultado da função resposta (absorbância). Tornou-se evidente que os 2 fatores que 


\section{9 a 22 de outubro de 2014 \\ Florianópolis/SC}

foram considerados no experimento, influenciam a resposta. Com a identificação das principais variáveis foi possível utilizar um procedimento de otimização (metodologia de superfície de resposta), capaz de modelar a variação da função resposta e, através da análise estatística, determinar as condições ótimas para a reação de complexação. Adicionalmente, a simulação de chuva utilizando dados regionais permitiu aplicar a metodologia desenvolvida e quantificar o glifosato no lixiviado do lisímetro de bancada que continha um latossolo oriundo da cidade de Paty do Alferes/RJ.

\section{REFERÊNCIAS}

COUTINHO, C. F. B., MAZO, L. H. complexos metálicos com o herbicida glifosato: revisão. Instituto de química de São Carlos, Universidade de São Paulo, São Carlos-SP, Quim. Nova, vol. 28, no. 6, 10381045, 2005.

DONG, W. H.; CHEN, X. C.; LANG, Z. M.; FAN, Y. X.; LIU, J.; Lihua. Jianyan., Huaxue. Fence. 1997, 33, 347

EMBRAPA SOLOS. Métodos para coletas de amostra de solos para análise. Disponível no site: http://www.cnps.embrapa.br/servicos/metodo_coleta.html acesso em 15 de março de 2013.

GALLI, A. J. B., MONTEZUMA M. C. Alguns aspectos da utilização do herbicida glifosato na agricultura. Glifosato Monsanto, ACADCOM Gráfica e Editora Ltda, 2005.

INMETRO, ORIENTAÇÕES SOBRE VALIDAÇÃO DE MÉTODOS DE ENSAIOS QUÍMICOS, Instituto Nacional de Metrologia, Normalização e Qualidade Industrial, DOQ-CGCRE-008 - Revisão 01, 2003.

INSTITUTO BRASILEIRO DE GEOGRAFIA E ESTATÍSTICA, IBGE Cidades, Rio de Janeiro. Disponível em http://cidades.ibge.gov.br/xtras/uf.php?lang=\&coduf=33\&search=rio-de-janeiro acesso em 05 de novembro 2013 14h.

JAN, M.R., SHAH, J., MUHAMMAD, M., ARA, B. Glyphosate herbicide residue determination in samples of environmental importance using spectrophotometric method. Journal of Hazardous Materials, 169, 742-745, 2009.

RAMALHO, J. F. G. P.; AMARAL SOBRINHO, N.M.B.; VELlOSO, A.C.X. Contaminação da Microbacia do Caetés com Metais Pesados pelo Uso de Agrotóxicos. Pesquisa Agropec. Brasileira. V.35, n.7. 2000. pp. 1289-1303.

SANCO/10684/2009. Method Validation and Quality Control Procedures for Pesticide Residues Analysis in Food and Feed. European Union. 2010.

ZHEMCHUZHIN, S. G.; GOROBETS, R. P.; Zh. Anal. Khim. 1989, 44, 741. 